\title{
Evaluation of the Compatibility of Repair Materials for Concrete Structures
}

\author{
Giri Venkiteela $^{1), *}$, Matthew Klein ${ }^{2)}$, Husam Najm², and Perumalsamy Naidu Balaguru ${ }^{3)}$
}

(Received October 21, 2016, Accepted June 16, 2017, Published online September 18, 2017)

\begin{abstract}
This study evaluates the compatibility of repair materials for concrete bridge decks. A new compatibility test set-up was designed and tested based on the concrete bridge deck cracking and delamination mechanism theory. The repair materials used in this study include lab formulated inorganic nano-aluminum silicates and commercially available organic two-part epoxy systems. Two different lab test-setups are proposed in this study: a prototype and a full-scale test. The developed test procedures were effective in communicating results in terms of compatibility of material properties, performance and quality. The prototype beams test can successfully serve as a small scale screening test providing insights on materials selection for the full-scale beam tests. The full-scale beams demonstrated the compatibility of the repaired system by providing data on authentic field conditions. Based on the observations it can be concluded that the proposed test setup is effective in examining the concrete bridge deck repair materials performance and selection, and compatibility in terms of mechanical properties and further guarantee the repaired structure safety.
\end{abstract}

Keywords: concrete repair, concrete bridge deck repair, compatibility test, organic and inorganic repair materials.

\section{Introduction}

Aging infrastructure is a growing concern for federal, state, and local governments across the United States and for many countries worldwide. The Federal Highway Administration (FHWA) estimates that one in nine of the nation's bridges is rated as structurally deficient and the average age of the nation's 607,380 bridges is about 42 years (ASCE (American Society of Civil Engineers) 2017; AASHTO (American Association of State Highway and Transportation Officials) 2008; NJDOT (New Jersey Department of Transportation) 2007). ${ }^{1}$ Thus county, city, state, and federal agencies need to increase budgets enormously to fix these deficient bridges. Many research studies focused on materials, systems and technologies to improve the life span of deficient bridge structures (FHWA (Federal Highway

\footnotetext{
${ }^{1)}$ New Jersey Department of Transportation, Trenton, NJ 08625, USA.

*Corresponding Author; E-mail: giri.venkiteela@dot.nj.gov

${ }^{2)}$ Technical Service Center, U.S. Department of the Interior Bureau of Reclamation, Denver, CO 80225, USA.

${ }^{3)}$ Department of Civil and Environmental Engineering, Rutgers, the State University of New Jersey, Piscataway, NJ 08854, USA.

Copyright $\odot$ The Author(s) 2017. This article is an open access publication
}

Administration) 2009; Floyd 2009; Stratton and McCollom 1974; Barbara and Wayne 1988; Camille and Debs 2007). It was reported that sound rehabilitation principles and techniques also play a crucial role in successful concrete rehabilitation process (Chase and Laman 2000; Arockiasamy 2000; FDOT (Florida Department of Transportation) 1999; NCHRP (National Cooperative Highway Research Program) Synthesis 375 2007).

In bridge superstructure, deck plays a crucial role in bridge performance and have a direct impact from flowing traffic and environment (such as snow accumulations and heavy rains etc.). It is extremely important for bridge owners to maintain its integrity and structural soundness for safety and sudden failures. Thus periodic inspection and maintenance is often required. In most bridges, the bridge decks are constructed using reinforced concrete. Regardless of the type of superstructure, the number and length of spans, and the type of concrete used, certain cracks develop in every reinforced concrete bridge deck (FHWA (Federal Highway Administration) 2009; Chase and Laman 2000; FDOT (Florida Department of Transportation) 1999). With time, these cracks lead to chloride penetration and corrosion of reinforcement. Corrosion of steel bars can lead to a concentration of internal stresses in the concrete and reduction in bond often resulting in further cracking and deterioration. Different types of concrete cracks are observed in concrete decks (Krauss and Rogalla 1996; ElSafty and Abdel-Mohti 2013; Ramseyer and Kang 2012; Soltani et al. 2013; Labib et al.

\footnotetext{
${ }^{1} \mathrm{http}: / /$ www.nytimes.com/2015/07/27/nyregion/aging-infrastructu re-plagues-nations-busiest-rail-corridor.html?_r $=0$.
} 
2013). These include vertical cracks which can be detected by visual inspection when there is no overlay and horizontal cracks, also called delaminations, which can cause a breaking-away of the concrete deck. Concrete delamination in bridge deck is a serious issue for bridge maintenance, because it cannot easily be identified as surface cracks and can lead to sudden failure of deck. Thus identifying and repairing of these cracks in concrete bridge decks is crucial for guaranteeing the quality and safety (Smoak 1996; PCA (Portland Cement Association) Final Report 1970; ACI (American Concrete Institute) Committee 224 report 2001).

Several repair procedures are often employed in the field for bridge decks based on location and size of cracks, which include Portland cement mortar filling, dry packing, epoxy bonded dry packing, shotcreting, epoxy bonded mortar filling, polymer concrete, alkyl-alkoxy siloxane sealing compound and resin injection etc. (Floyd 2009; Stratton and McCollom 1974; Soriano 2002; Davidovits 1991; Matthew et al. 2011). Both narrow and wide dormant cracks (in dormant cracks width does not change over time may be repaired by routing and sealing, which is the simplest and most common technique for crack repair. Narrow, dormant cracks may be effectively sealed by epoxy injection (Do and Kim 2012; Iowa Department of Transportation 2008; Rodler et al. 1989; Leivo et al. 2006). In some cases concrete structural elements can be bonded together with repair materials. ${ }^{2}$

Currently, There are various materials can be used for concrete deck crack repair which include Portland cement binders, polymers such as high molecular weight methacrylate and low viscosity epoxies etc. (Floyd 2009; Barbara and Wayne 1988). Among all these materials, the most commonly used repair materials are organic epoxies. In recent years, many research studies focused on geo-polymer materials for infrastructure construction and maintenance. It was observed that the performance of these inorganic compounds (Soriano 2002; Davidovits 1991; Hammell 2000; Garon 2000; Richard et al. 1997; Woo et al. 2008) are superior over traditional organic materials. It is certain that these newly developed materials such as inorganic compounds has huge role to play in future infrastructure maintenance. It is always debatable which materials should be used for bridge deck repair and it is often big challenge for agencies and bridge owners to make such decisions. For concrete structures under service conditions (with both traffic and environmental loadings), bond strength is sometime evaluated as an important property for crack repair materials. There are several standard test methods available to evaluate bond strength indirectly using different types of repaired concrete samples (ASTM (the American Society for Testing and Materials) 2005; ASTM (the American Society for Testing and Materials) 2008; ASTM (the American Society for Testing and Materials) 2013).

To better understand the performance of repair materials, it is important to study their compatibility along with bond strength. However, there are no standard methods for

\footnotetext{
${ }^{2} \mathrm{http} / / / \mathrm{www} . u s c p r o d u c t s . c o m /$ featured-projects/tappen-zee-bridge/.
}

determining the compatibility of repair materials with respect to concrete substrate. For the repair material to be completely compatible with concrete, the internal stresses would be able to be transferred across the repair plane and distribute over the entire cross-sectional area of the concrete. When concrete is used in flexural applications tensile reinforcement is required due to the low tensile capacity of the concrete. In concrete, steel reinforcement is added to provide the missing tensile reinforcement. Since the capacities of each material are different, the equivalent area in the concrete is greater to counteract the tensile forces in the steel in order to balance out the flexural internal stresses (Elgabbas et al. 2016). However, the effective area of the concrete is only a quarter to a fifth of the total crosssectional area of the beam. When defects occur in this compression zone, the internal stresses must concentrate around the defect and reduce the load capacity of the concrete. If a repair material is used, it should be able to bond the concrete together so that the entire load resisting area can be utilized. When a beam is composed of several smaller cross-sections that are not mechanically or chemically fastened to one another, the total flexural capacity of the beam is controlled by the smallest cross-section along the span. Thus if the compression zone of the concrete is removed, the stresses must redistribute to the concrete area closer to the tensile fibers which reduces the moment arm of the flexural strength and reduces the moment capacity of the beam.

The objective of this study is to evaluate the compatibility of repair materials with respect to the corresponding concrete substrate. The repair materials used in this study include lab formulated inorganic nano-aluminum silicates and commercially available organic two-part epoxy systems. A compatibility test for the repair materials was developed and tested in this study, based on the concrete bridge deck cracking and delamination mechanism theory. Two different lab test-setups are proposed in this study: a prototype and a full-scale test. The developed test procedures were effective in producing results for repair materials properties and for performance and quality in terms of compatibility. Based on the observations it can be concluded that the proposed test setup is effective in examining the concrete bridge deck repair materials performance and selection, and compatibility in terms of mechanical properties and further guarantee the repaired structure safety.

\section{Concrete Cracking and Delamination}

Delaminations often occur in bridge decks due to corrosion in the reinforcing bars causing tensile stresses to the concrete and flexural loading conditions inducing shear stresses along the top mat of reinforcement (Krauss and Rogalla 1996; ElSafty and Abdel-Mohti 2013). A typical bridge consists of vertical supports spanned by horizontal beams. The bridge deck is supported on several beams which are typically spaced between 4 feet to 10 feet. The 


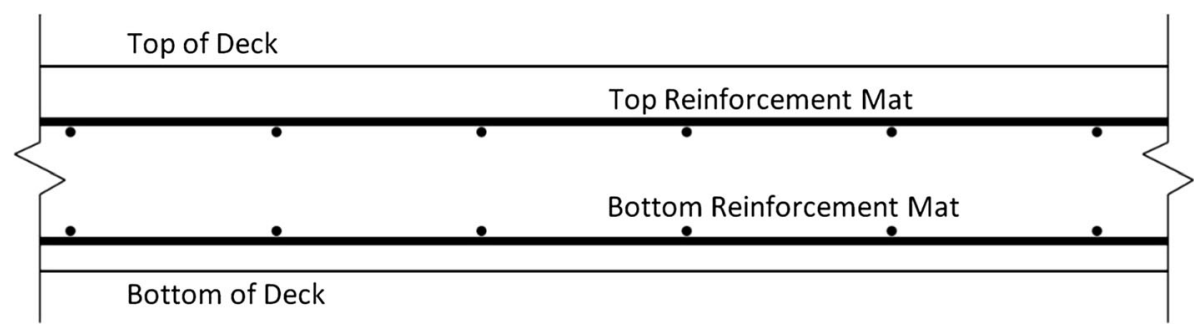

Fig. 1 Typical reinforcement placement in bridge deck.

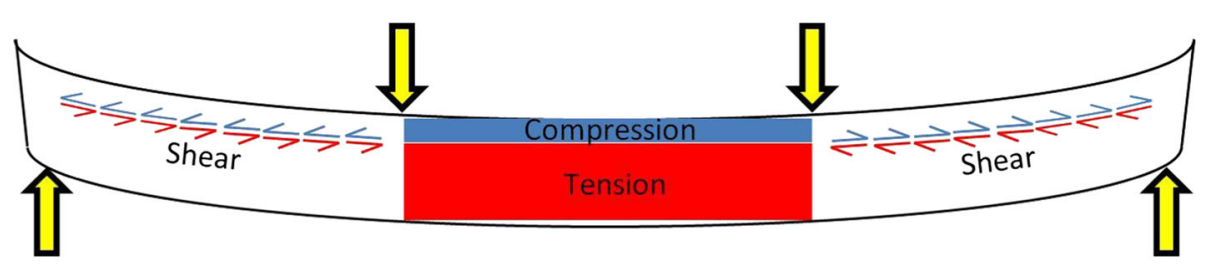

Fig. 2 Internal stress distribution in third-point bending.

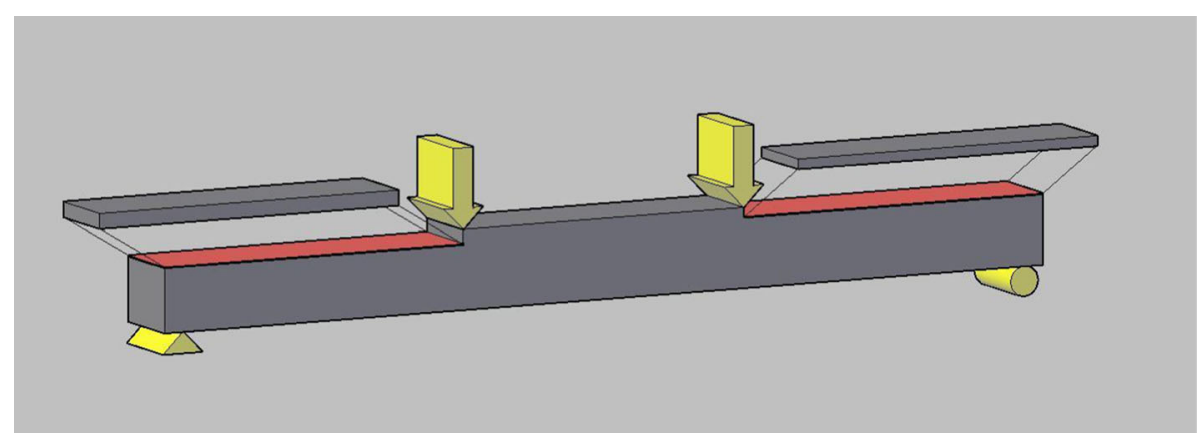

Fig. 3 Diagram of compatibility beam.

bridge deck is usually anywhere from 8 inches to 12 inches thick but can be greater if required. Usually the deck features two layers of reinforcement called mats and consists of two sets of bars located perpendicular to each other for transverse and longitudinal flexural loads near the outer edge of the concrete as shown in Fig. 1.

When concrete is loaded in flexure, small flexural cracks form as a result of the transfer of tensile forces from the concrete to the steel reinforcement. In addition, when loads are applied to the superstructure, the opposing tensile and compression stresses from the ensuing flexural forces provide shear loads at or near the neutral axis (see Fig. 2). Since the strength of concrete and steel are different the neutral axis is not located at the mid-point as would be the case in a homogenous material but rather can be located at approximately $1 / 5$ the thickness of the deck. This location often corresponds to the location of one of the two reinforcing mats described above. Most concrete decks are cast continuously across the supporting girders and therefore the compression and tensile inducing shear zones of the deck alternate with respect to the girder spacing. The zones located at the top surface of the bridge deck are where the maximum stresses can occur- "compressive" shear stresses near the deck supports and "tensile" shear stresses at the midsection.

Another force that contributes to bridge deck delaminations is caused by expansion of the steel reinforcement due to corrosion. Water has been known to infiltrate the steel reinforcement by way of the flexural cracks that form during service loads. When water, oxygen and steel combine, the oxidized product forms known commonly as rust. This form of iron is known to be less dense than the parent materials thereby exerting tensile stresses in the confining concrete around the bar.

Therefore, the main stresses acting on the concrete causing delaminations, spalling, and eventually loss of the concrete cover and potholes, are tensile forces from corroding steel reinforcement and/or shear forces resulting from the opposing compressive and tensile stresses inherent in flexural loading. This analysis is used to design a test set-up for finding how effective the concrete repair is and determine repair material compatibility with concrete. A beam is designed with notches at either end at the compressive reinforcement (top mat) layer (see Fig. 3). Then blocks are formed to fill the notches to the size of a rectangular beam after being fixed to the notched beam using the repair material.

\section{Materials}

\subsection{Repair Materials}

In this study, the inorganic and organic repair materials that were selected include a lab formulated inorganic nano 
Table 1 Mix proportions for small and full-scale beam specimens.

\begin{tabular}{c|c|c|c|c|c}
\hline Material & Coarse aggregates & Fine aggregates & Water & Cement & SuperP \\
\hline \hline Quantity & $945 \mathrm{lb} / \mathrm{yd}^{3}$ & $1647 \mathrm{lb} / \mathrm{yd}^{3}$ & $424 \mathrm{lb} / \mathrm{yd}^{3}$ & $817 \mathrm{lb} / \mathrm{yd}^{3}$ & $9.3 \mathrm{lb} / \mathrm{yd}^{3}$ \\
\hline
\end{tabular}

alumino-silicates and commercially available two part epoxy system. The epoxy resin boasts low viscosity, high modulus and non-shrinkage properties. The reported viscosity, given in the product data sheet, is about $280 \mathrm{cps}$ and cures in approximately $24 \mathrm{~h}$ (SealBoss 2012). The inorganic mix design was obtained based on materials performance on different tests including flexural tests, slant shear tests, freeze/thaw durability and wetting durability tests (Matthew 2013). The final mix design of the inorganic material has standard silica/alumina ratio and optimized zinc oxide activator.

\subsection{Concrete Mix-Design}

The mix design for the prototype small beams and the fullscale beams include Portland Type I cement, coarse aggregates, fin aggregates (sand), fly ash, water, and superplasticizer (Matthew 2013). The mix design proportions are shown in Table 1. The samples were removed from molds after a minimum of $24 \mathrm{~h}$ and were cured in a in a fog room for a minimum of 28 days.

\section{Test Procedure}

\subsection{Concrete Beams Design and Casting 4.1.1 Prototype Beams}

In order to test compatibility between the repair materials and concrete, small-scale (prototype) beams samples were prepared and cast. The small beam specimens were helpful in verifying some assumptions and the observations from their testing and test results helped in designing representative full-scale beams and avoiding problems during the test itself. The dimensions were scaled from the proposed fullscale samples with the length fixed at 14 inches. The concrete in the flexural samples was tested with a compressive strength of $5500 \mathrm{psi}$. The dimensions for the width and depth were $1-1 / 8$ inch. The notches were $5 / 16$ inch and 1/4 inch for the approximate neutral axis. Length of the notch was set

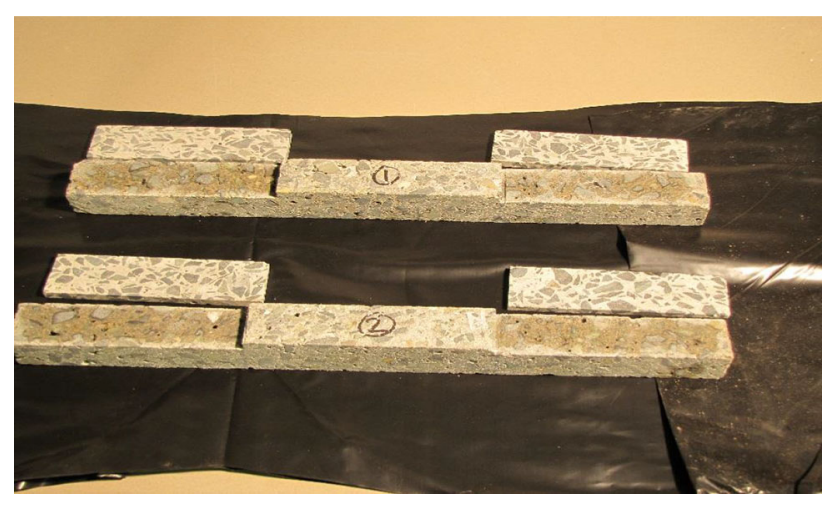

Fig. 4 Prototype beams. at $L / 3$ and was equal to 4.75 inches including the 1 inch overhang at the end as shown in Fig. 4. Since the beams were created from existing concrete without internal tensile reinforcement, the beams were strengthened using carbon fibers after the notches were repaired with the specified repair materials as shown in Fig. 5. Two tows of $35 \mathrm{k}$ Zoltec Panex fibers were fixed to the bottom of the beams using a typical 2-part epoxy for bonding carbon fibers to concrete beams.

The beams were notched and then repaired using selected inorganic and organic repair compounds. Two similar inorganic materials compounds (inorganic 1 and inorganic 2) were formulated based on silica/alumina ratio as specified in Sect. 2.1. Similarly for the organic materials, two epoxy systems (epoxy 1 and epoxy 2) were used (Matthew 2013).

After the repaired beams were allowed to cure at room temperature for at least one week they were tested using MTS Sintech 10/GL load testing machine with 10 kip load capacity as shown in Fig. 6.

\subsubsection{Full-Scale Beams}

The dimensions of the full-scale beam were chosen to accommodate equipment where a 600 kip beam testing machine was used. The machine is optimized for 8 foot

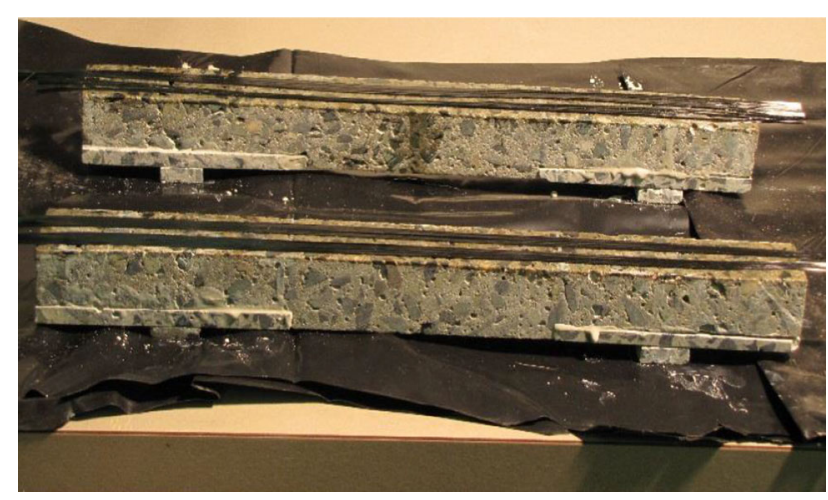

Fig. 5 Completed prototype beams.

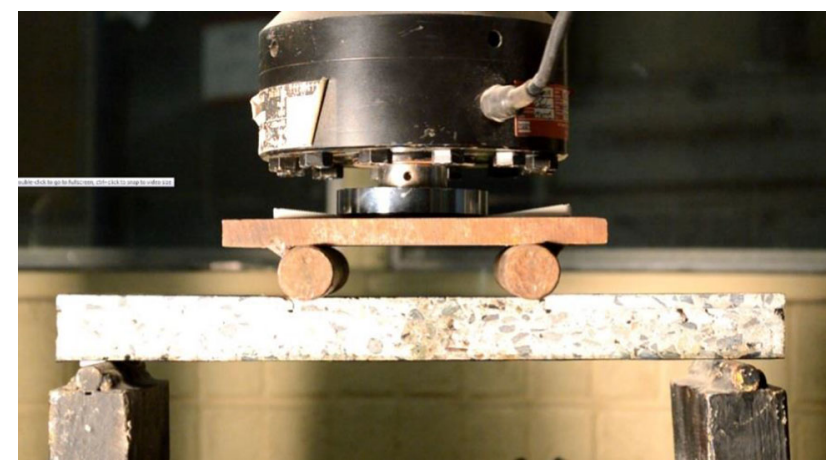

Fig. 6 Prototype beam test.

438 | International Journal of Concrete Structures and Materials (Vol.11, No.3, September 2017) 
length beams and is a common bridge girder spacing. The depth of the beam, 8 inches, was chosen as a common bridge deck thickness and the width was kept at 8 inches to give a depth to width ratio of 1 . In addition, the thickness satisfies target neutral axis calculations by placing the axis between 1 and $1 / 2$ to 2 inches (approximately $1 / 5-1 / 4$ the depth of the beam). This also explains the choice of the notch depth at $1-1 / 2$ on one side and 2 inches on the other so that the full range of the neutral axis can be affected and maximum shear can be applied to the repair. The full-scale beam elevation dimensions are shown in Fig. 7.

As for tensile reinforcement, four \#6 bars were used to create an over-reinforced design as shown in Fig. 8, to insure the beam will reach maximum shear in the neutral axis. In an over-reinforced beam, the ultimate failure occurs in the compression zone. The maximum load of the beam was found to be at $19.17 \mathrm{kip}$ in each load point (third point bending) for a total of $38.34 \mathrm{kip}$. However, since the beam is not to be tested destructively and to represent normal bridge loading condition which include respective factors of safety of the inherent error in the load and material resistance, the beam is only loaded to approximately $60 \%$ of the ultimate load corresponding to two point loads of $11.5 \mathrm{kip}$ spaced at one-third the length of the beam or 23.0 kip total. This load also satisfies the cracking load which is found to be $1.61 \mathrm{kip}$, meaning that the reinforcement will be loaded during the test. Minimum shear reinforcement in the critical areas of the beam is provided using \#2 stirrups spaced at $\mathrm{d} / 2=3-1 / 2$ inches over the outside one-third of the span. The concrete shear resistance is sufficient in the center third of the beam simplifying the design and construction of the beam. Minimum concrete cover of $3 / 4$ inch is supplied in all directions around the reinforcing steel.

Five full-scale beams are cast in that two beams used as control beams, one repaired with the inorganic repair

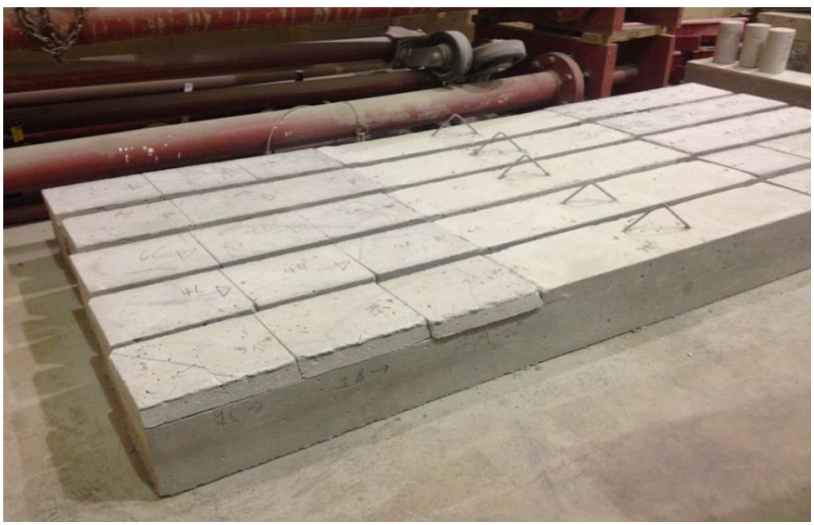

Fig. 9 Notched full-scale beams.

material, one repaired with epoxy, and one used as contingency plan beam against beam damage (see Fig. 9). The organic and inorganic materials for the full-scale study were selected based on their performance in prototype testing (Sect. 4.1). The two control beams are a full-sized 8 inch square beam without notches and a notched beam to give the expected upper and lower bounds on the load-deflection curve.

The differences between the prototype beams and the fullscale beams are that the repair blocks are not full length, the tensile reinforcement in the full-scale beams is steel and the compressive strength of the concrete is lower at 4600 psi. The reason for the sectional repair blocks is that given the deflections of the reinforced concrete beam, full length blocks might cause complex stresses on the blocks that are difficult to account for. By dividing the blocks into sections, pure shear stress along the repair can be applied. The reason for the steel reinforcement is to utilize steel as the tensile reinforcement as typical in traditional concrete bridge decks.

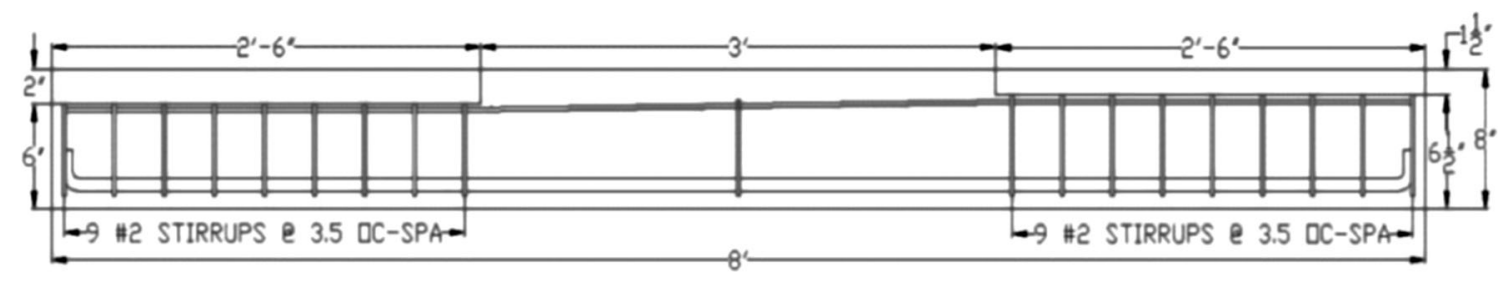

Fig. 7 Full-scale beam elevation dimensions.

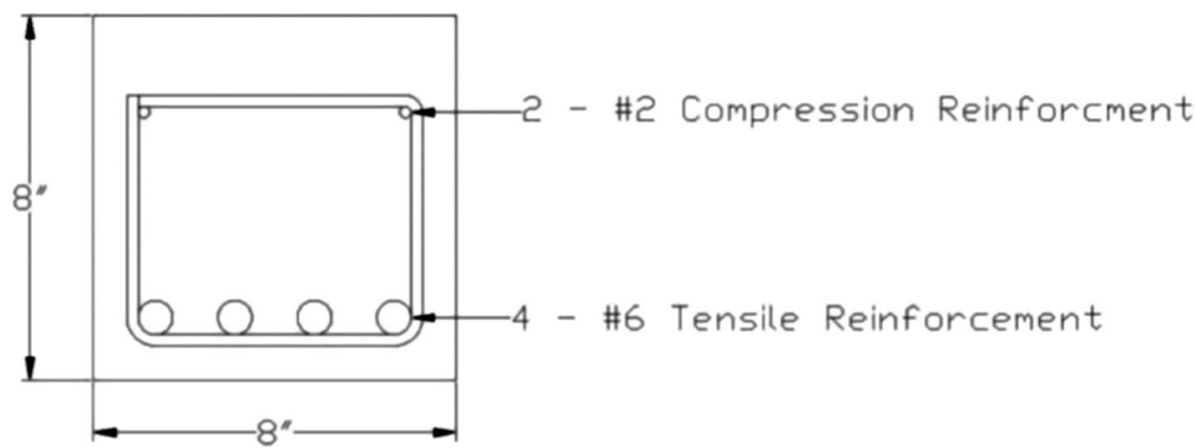

Fig. 8 Full-scale beam cross-section dimensions. 
The lower compressive strength was specified for the fullscale tests to simulate typical field conditions.

The repair was prepared by wrapping half of the horizontal repair plane with tape to prevent the repair material from leaking out and causing voids. The repair materials were applied by pouring the mix in the dam created by the tape and attach each block section into place. The blocks were pressed firmly into the repair material. Excess amounts of material were not allowed to drain so as to reduce the amount of voids. If the blocks were higher than the middle compressive zone of the concrete beam, it would not affect the overall strength of the beam since the strength is limited by the smallest moment arm in the pure flexural zone of the loading arrangement. As each block was placed into position, the vertical face mating with the beam or another block was coated with repair material and pressed together. Once all blocks were in place, the vertical crack was sealed with tape and the repair mix was poured over the crack to completely fill all the voids. Once the two beams were repaired, they were allowed to cure for a minimum of 7 days before the tape was removed. The cracks were inspected for presence of voids and no voids were observed.

\subsection{Instrumentation}

The data collection system used in this study gathered data points that includes the loads and deflection at the midpoint and at each load point to create a load-deflection profile for each beam (see Fig. 10). These data were used to determine the effective stiffness of each beam and allow for easy comparison to check for effectiveness of repair. In addition to the loads and deflection, lines were drawn on the side surfaces of the repaired beams crossing over the repair plane so that the shear movement can be monitored. Initially, the use of crack monitoring equipment was specified but the dimensions of the notches would not allow for installation of the gauges (Fig. 11).

The length of the test included a preloading period to seat the support and load equipment and zero the gauges. Then, the beams were loaded to $60 \%$ of failure at a static loading rate (between 15 and $20 \mathrm{lbs}$ per second) for a total of about $15 \mathrm{~min}$ for the entire test. Once the specified load is reached, scale pictures of the crack lines are taken and then the beam is unloaded and the entire test is repeated two more times for a total of three loading cycles to provide a complete stiffness profile of the beam.

The system used to gather the load and deflection data are a series of sensors that are connected to a computer using USB ports. Two load cells are located under each load and three deflection gauges are positioned at the midpoint for ultimate deflection and under each load to allow for computation of a deflection curve. The data is collected by a proprietary software package (2016). This software logs the data collected into a.csv file for importing into any spreadsheet program for further analysis. The data collection rate was set at $1 \mathrm{~s}$ intervals.

\section{Results and Discussions}

\subsection{Prototype Samples}

From Fig. 12, it can be observed that the stiffness is greater in the inorganic repaired beam and the loads are higher in the same beams. Both of these outcomes were predicted in theory. Recall that if the repair material was more compatible with concrete, then it would behave as a single homogeneous beam and offer the same stiffness and

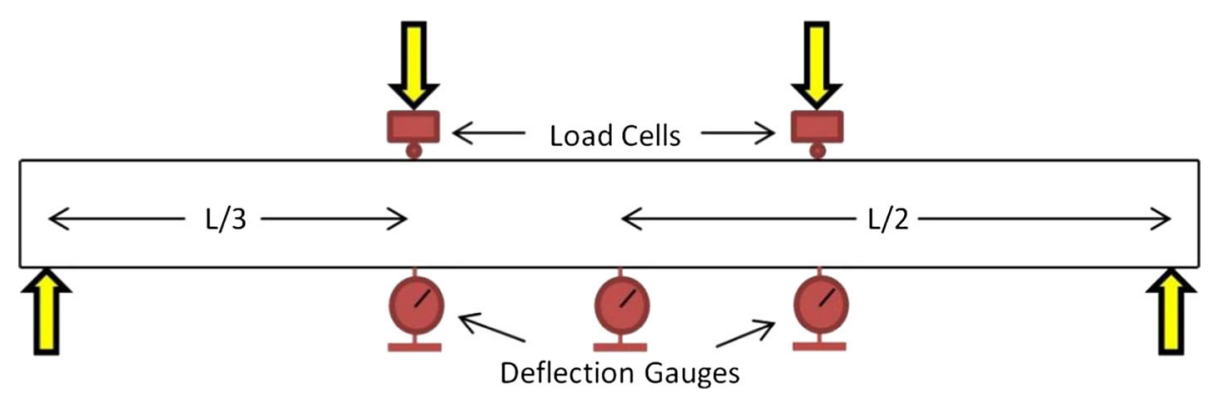

Fig. 10 Instrumentation set-up.
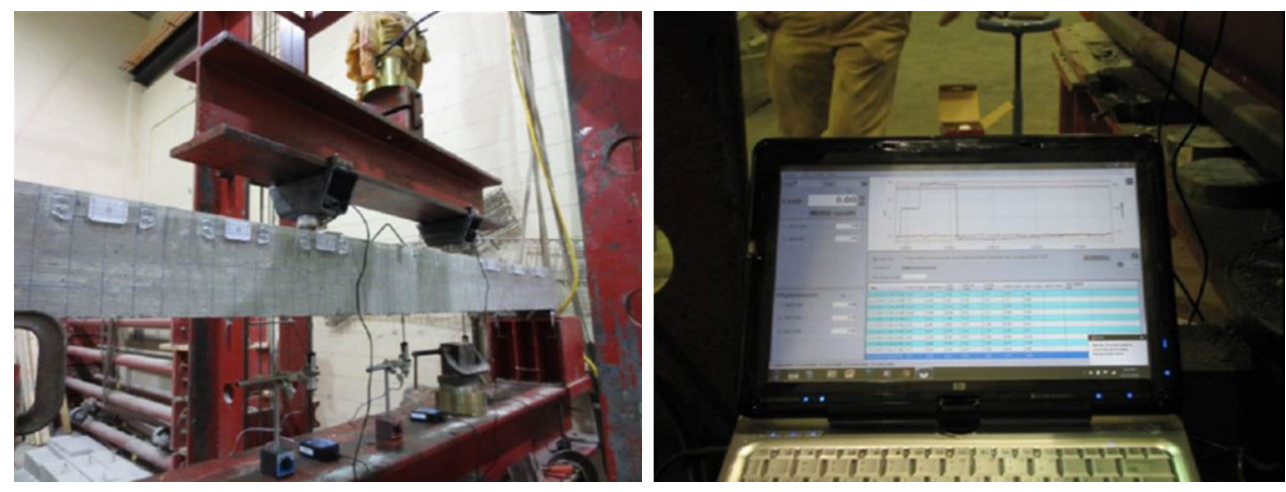

Fig. 11 Full-scale beam test instrumentation. 


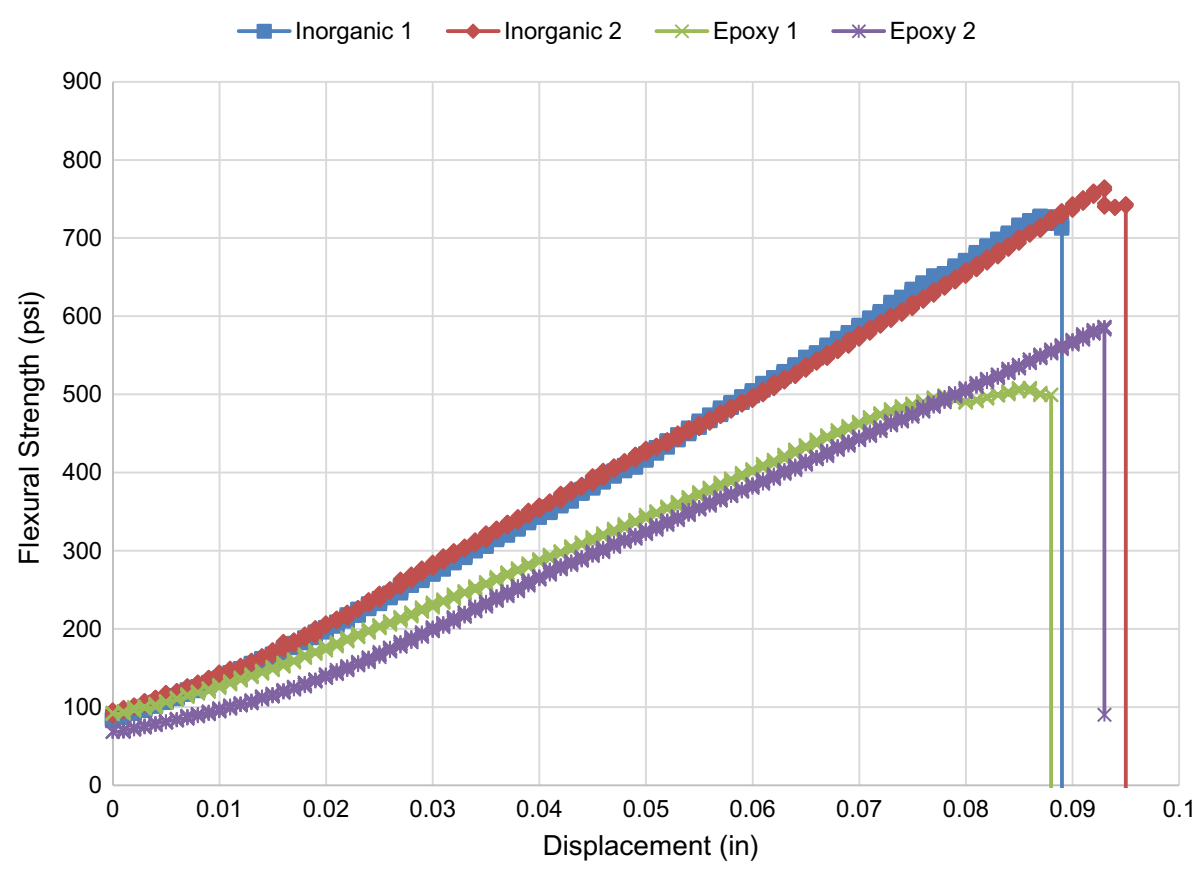

Fig. 12 Prototype beam results.
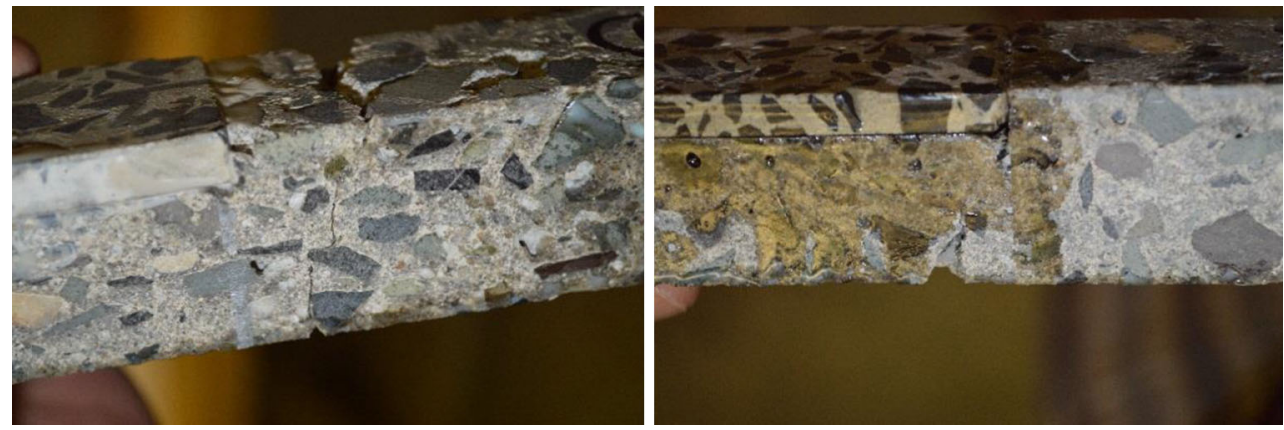

Fig. 13 Prototype failures; inorganic (left), organic (right).

load capacity. If the repair material could not transfer stresses across the repaired plane, the strongest beam action would be in the smallest dimension (the weakest limit on the beam). Hence, the lower values for the beams repaired with the organic epoxy. The beams deflected more with less load acting as a beam that could not rely on the compressive strength of the notched block repair.

All beams were failed at similar strain due to debonding of the carbon fibers as predicted. The beams repaired with the inorganic material failed at an average of $747 \mathrm{psi}$ and the beams repaired with the epoxy failed at an average of 547 psi. The average deflections were 0.0913 inches. Both inorganic repair beams fracture point occurred in the middle third of the beam as most third-point loading test usually do. The epoxy repaired beams fracture point was located at the load point or outside of the middle third of the span as shown below in Fig. 13. (Notches were added outside of the middle third of the span on either side).

\subsection{Full-Scale Beams}

The full-scale tests performed similar to the prototype tests. Here the repaired inorganic aluminosilicate beams showed similar stiffness to the solid beam. The repaired organic epoxy beam behaved just like the notched beam that had not been repaired at all. The curvature (shown in Fig. 14) shows that the notched and epoxy repaired beams had internal hinges in at the load points at L/3. The solid and aluminosilicate repaired beams had an even curvature all across the span.

In addition, the load/deflection graphs show a similar trend (Fig. 15). Both the notched and epoxy repaired beams showed lower stiffness with increased deflection over the same loading. The inorganic repaired and solid beams exhibited higher stiffnesses. A model of a solid beam was also generated using the cracked moment of inertia (Matthew 2013) and the inorganic repaired and solid beams followed closely to the model with slight deviations due to imperfections in the cast beams.

Both of these results clearly show that the epoxy repaired beam did not benefit from the repair. The beam had the same load and deflection reaction as the beam that was completely notched without repair of any type. The beam repaired with the inorganic polymer showed the same stiffness as the calculated model and slightly higher stiffness than the actual 


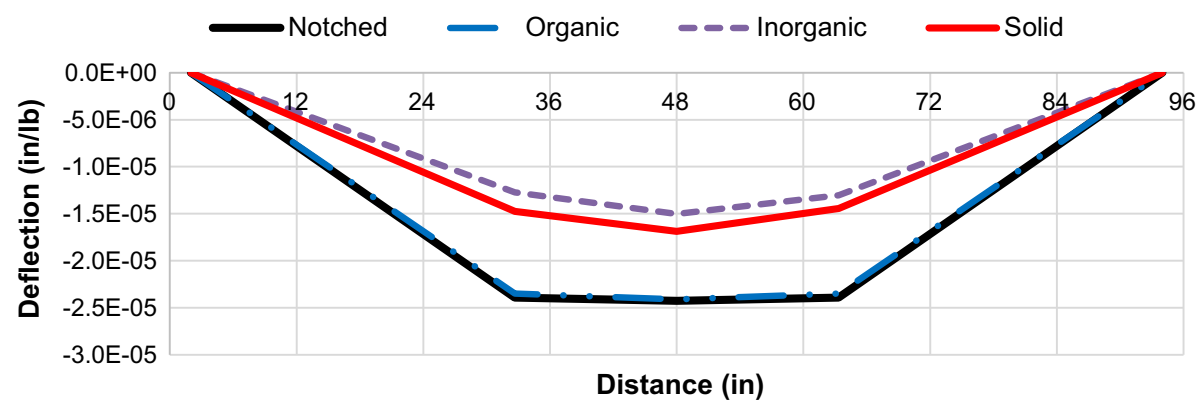

Fig. 14 Full-scale beam curvature comparison.

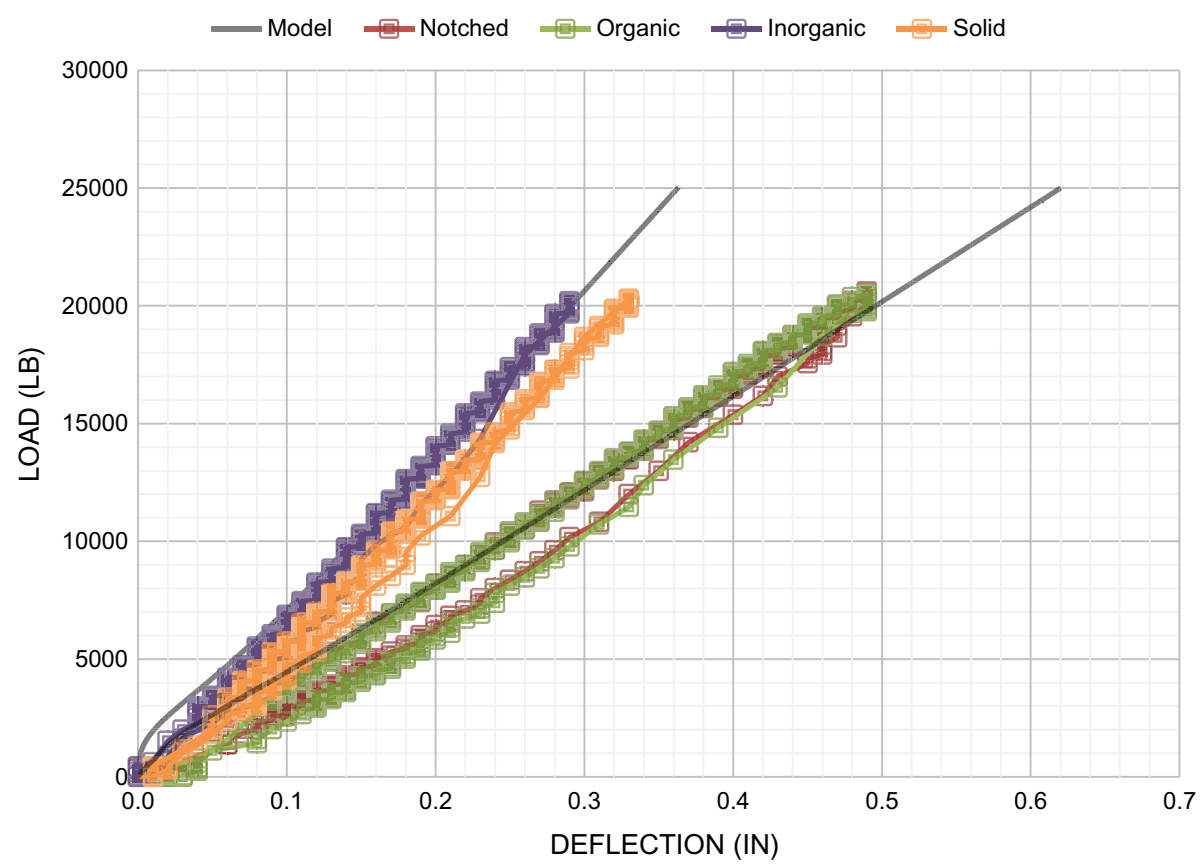

Fig. 15 Full-scale beam comparison.

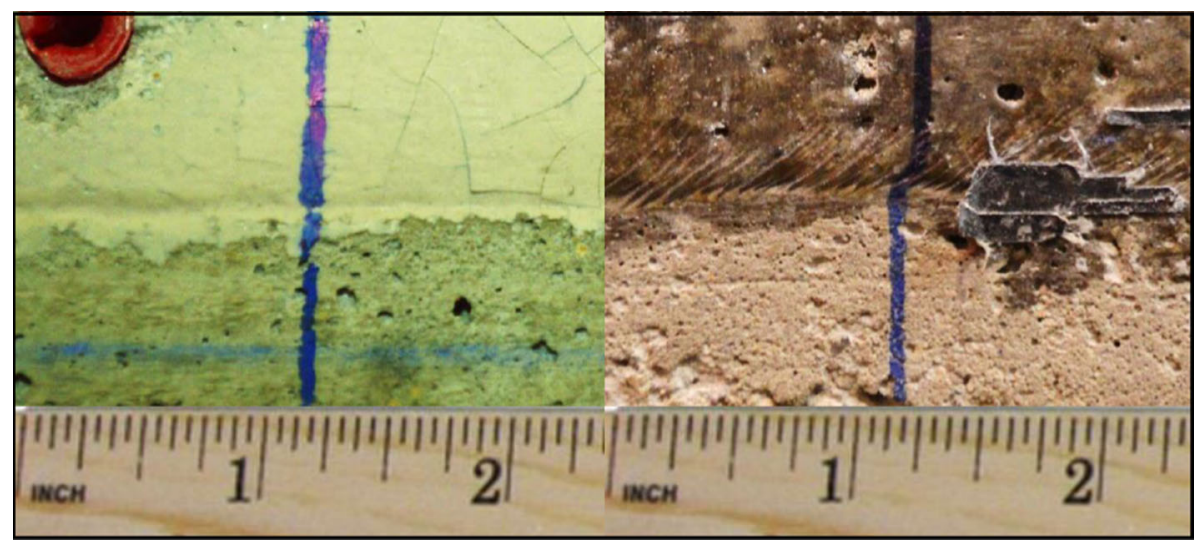

Fig. 16 Shear movement comparison; inorganic (left), organic (right).

solid unnotched beam. Of course, this is due to imperfections in the beam but the point is still poignantly made, that the inorganic epoxy allows the internal forces to transfer across the repair plane and include the compression block in the resolution of the moment arm in the flexural strength of the beam. Figure 16 illustrate the shifting of the blocks with respect to the beam. The flexibility of the organic epoxy is evident in the offset of the detection lines across the horizontal crack. The inorganic repaired beam does not have any apparent movement and indicates that the repair of the concrete using the inorganic epoxy will be able to provide stress transfer and concrete compatibility for the structural 


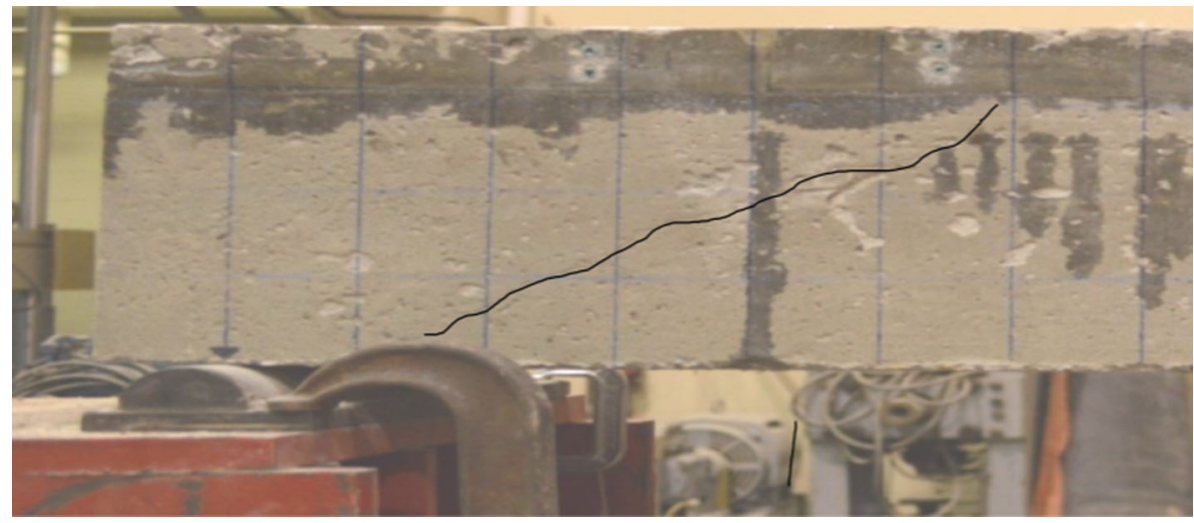

Fig. 17 Shear crack in epoxy repaired beam.

element. This will allow that repaired component greater resistance against additional delamination cracking and prolong the life of the structure.

In addition to the experimental evidence of the incompatibility of the epoxy repair system and the concrete, both the notched and epoxy repaired beams featured shear cracking in the outside third of the beam. This indicated that the minimum shear reinforcement set by the ACI 318 code requirement of half the distance from the extreme compression fiber to the centroid of the tensile reinforcement was too large (ACI (American Concrete Institute) 2011). In essence, the actual extreme compression fiber was not the top of the block in the case of the epoxy repaired beam, but the top of the notch as seen in Fig. 17.

\section{Conclusions}

The following conclusions can be drawn from this study:

1. The prototype beams showed the feasibility of full-scale beams for use as effective tests of compatibility of repair materials with concrete because of their success on the small scale.

2. In prototype testing, the beams repaired with the inorganic material failed at an average of 747 psi and the beams repaired with the epoxy failed at an average of 547 psi. The average deflections were 0.0913 inches.

3. The prototype tests indicated that the organic repair systems were not able to provide the same strength resistance of the inorganic repaired beams. These tests could not show the range of repair that each system offered since no control beams were used.

4. The full-scale beams demonstrated the compatibility of the repair system by providing real data on the effectiveness of the repair material.

5. The inorganic repaired beams featured higher stiffness, no detectible shear slippage along the repair interface, no failure cracking and loading behavior similar to both the calculated model and the solid unnotched beam.

6. The organic repaired system featured lower stiffness, shear slippage along the repair plane, shear cracking near the reaction supports indicating decreased depth from the extreme compression fiber to the centroid of the tensile reinforcement, and loading behavior surprisingly similar to the notched control beam.

7. Finally, it can be concluded that proposed testing methodology along with standard testing methods can greatly help to examine the performance of concrete repair materials. It can also help in the selection of suitable materials in terms of compatibility and repaired structural safety.

\section{Open Access}

This article is distributed under the terms of the Creative Commons Attribution 4.0 International License (http:// creativecommons.org/licenses/by/4.0/), which permits un restricted use, distribution, and reproduction in any medium, provided you give appropriate credit to the original author(s) and the source, provide a link to the Creative Commons license, and indicate if changes were made.

\section{References}

AASHTO (American Association of State Highway and Transportation Officials). (2008). Bridging the gap. Washington, DC: AASHTO.

ACI (American Concrete Institute) Committee 224 report. (2001). Control of cracking in concrete structures. Farmington Hills, MI.

ACI (American Concrete Institute). (2011). Building code requirements for reinforced concrete-ACI 318. Farmington Hills, MI.

Arockiasamy, M. (2000). Evaluation of conventional repair techniques for concrete bridges. Tallahassee, FL: FDOT (Florida Department of Transportation).

ASCE (American Society of Civil Engineers). (2017). 2017 Report Card for America's Infrastructure. Reston, VA.

ASTM (the American Society for Testing and Materials). (2005). Standard test method for bond strength of epoxyresin systems used with concrete by slant shear. ASTM C882-05, West Conshohocken, PA. 
ASTM (the American Society for Testing and Materials). (2008). Standard test method for flexural strength of concrete using simple beam with third-point loading. ASTM C78-08, West Conshohocken, PA.

ASTM (the American Society for Testing and Materials). (2013). Standard test method for tensile strength of concrete surfaces and the bond strength or tensile strength of concrete repair and overlay materials by direct tension (pull-off method). ASTM C1583/C1583 M - 13, West Conshohocken, PA.

Barbara, S. J., \& Wayne, S. F. (1988). Bridge deck hollow plane repair using injected epoxy. Topeka, KS: KDOT (Kansas Department of Transportation).

Camille, A. I., \& Debs, P. (2007). Experimental study of epoxy repairing of cracks in concrete. Construction and Building Materials, 21(1), 157-163.

Chase, S., \& Laman, J. (2000). Dynamics and field testing of bridges. Transportation in The new Millennium: State of the Art and future Directions, Perspectives from TRB (the Transportation Research Board Standing) Committees. Washington, DC.

Davidovits, J. (1991). Geopolymers: Inorganic polymeric new materials. Journal of Thermal Analysis, 37, 1633-1656.

Do, J. Y., \& Kim, D. K. (2012). AHP-based evaluation model for optimal selection process of patching materials for concrete repair: Focused on quantitative requirements. International Journal of Concrete Structures and Materials, 6(2), 87-100.

Elgabbas, F., Ahmed, E., \& Benmokrane, B. (2016). Experimental testing of concrete bridge-deck slabs reinforced with basalt FRP bars under concentrated loads. ASCE Journal of Bridge Engineering, 21(7), 04016029.

ElSafty, A., \& Abdel-Mohti, A. (2013). Investigation of likelihood of cracking in reinforced concrete bridge decks. International Journal of Concrete Structures and Materials, 7(1), 79-93.

FDOT (Florida Department of Transportation). (1999). Bridge maintenance and repair handbook. Tallahassee, FL: FDOT. http://www.fdot.gov/maintenance/STR/IN/Maintenance and_Repair_Handbook_08-13-11.pdf.

FHWA (Federal Highway Administration). (2009). Annual Materials Report on New Bridge Construction and Bridge Rehabilitation: National Bridge Inventory (NBI). Washington, DC.

Floyd, S. D. (2009). Repairing Bridge Deck Cracks. Epoxy bonding is an economical solution. Concrete Construction Magazine. http://www.concreteconstruction.net/products/dec orative-concrete-surfaces/repairing-bridge-deck-cracks_o.

Garon, R. J. (2000). Effectiveness of high strength composites as structural and protective coatings for structural elements. Dissertation. New Brunswick, NJ: Rutgers, the State University of New Jersey.

Hammell, J. A. (2000). The influence of matrix composition and reinforcement type on the properties of polysialate composites. Dissertation. New Brunswick, NJ: Rutgers, the State University of New Jersey.
Iowa Department of Transportation. (2008). Inspection and acceptance epoxy resins. http://www.iowadot.gov/erl/ archives/2009/oct/IM/content/491.19.pdf.

Krauss, P. D., Rogalla, E. A. (1996). Transverse cracking in newly constructed bridge decks: NCHRP Report 380. Washington, DC: Transportation Research Board, National Research Council.

Labib, E. L., Mo, Y. L., \& Hsu, T. T. C. (2013). Shear cracking of prestressed girders with high strength concrete. International Journal of Concrete Structures and Materials, 7(1), 71-78.

Leivo, J., Mika, L., Cilaine, V. T., Janne, P., Jessica, R., Erkki, L., et al. (2006). Sol-gel synthesis of a nanoparticulate aluminosilicate precursor for homogeneous mullite ceramics. Journal of Materials Research, 21(5), 1279-1285.

Loadstar Sensors. (2016). Software for load sensors. http:// www.loadstarsensors.com/software.html?view=default.

Matthew, K. (2013). Nondestructive repair and rehabilitation of structural elements using high strength inorganic polymer composites. Dissertation. New Brunswick, NJ: Rutgers, the State University of New Jersey.

Matthew, K., Venkiteela, G., Husam, N., \& Balaguru., P. N. (2011). Nanoscale materials for non-destructive repair of transportation infrastructures. In Proceedings of SPIE 7983, Nondestructive Characterization for Composite Materials, Aerospace Engineering, Civil Infrastructure, and Homeland Security. San Diego, CA.

NCHRP (National Cooperative Highway Research Program) Synthesis 375. (2007). Bridge inspection practices. Washington, DC.

NJDOT (New Jersey Department of Transportation). (2007). Highways carrying bridges in New Jersey. http://www. state.nj.us/transportation/refdata/bridgereport102007.pdf.

PCA (Portland Cement Association). (1970). Final report: Durability of concrete bridge decks. Skokie, IL.

Ramseyer, C., \& Kang, T. H. K. (2012). Post-damage repair of prestressed concrete girders. International Journal of Concrete Structures and Materials, 6(3), 199-207.

Richard, L. E., Balaguru, P. N., Andrew, F., Usman, S., Joseph, D., \& Michel, D. (1997). Fire resistant aluminosilicate composites. Fire and Materials, 21(1), 67-73.

Rodler, D. J., Whitney, D. P., Fowler, D. W., \& Wheat, D. L. (1989). Repair of cracked concrete with high molecular weight methacrylate monomers. Polymers in concrete advantages and applications: ACI SP-116, Farmington Hills, MI.

SealBoss. (2012). Sealboss 4040 LV Epoxy Resin. Product Data Sheet, SealBoss Corporation, Santa Ana, CA.

Smoak, W. G. (1996). Guide to concrete repair. Denver, CO: Bureau of Reclamation.

Soltani, A., Harries, K. A., \& Shahrooz, B. M. (2013). Crack opening behavior of concrete reinforced with high strength reinforcing steel. International Journal of Concrete Structures and Materials, 7(4), 253-264.

Soriano, A. (2002). Alternative sealants for bridge decks: Final report. Pierre, SD: South Dakota Dept. of Transportation Office of Research. 
Stratton, F. W., \& McCollom, B. F. (1974). Repair of hollow or softened areas in bridge decks by rebonding with injected epoxy resin or other polymers. Topeka: State Highway Commission of Kansas.
Woo, R. S. C., Honggang, Z., Michael, M. K. C., Christopher, K. Y. L., \& Jang-Kyo, K. (2008). Barrier performance of silane-clay nanocomposite coatings on concrete structure. Composites Science and Technology, 68(14), 2828-2836. 